\title{
Endometrioma mimicking ovarian malignancy in a post-menopausal woman
}

\section{Vijay Zutshi ${ }^{1}$, Shreshtha Gupta ${ }^{1 *}$, Charanjeet Ahluwalia ${ }^{2}$, Monica R. ${ }^{2}$}

\begin{abstract}
${ }^{1}$ Department of Obstetrics and Gynecology, ${ }^{2}$ Department of Pathology, Vardhman Mahavir Medical College and Safdarjung Hospital, New Delhi, India
\end{abstract}

Received: 20 June 2021

Accepted: 13 July 2021

\section{*Correspondence:}

Dr. Shreshtha Gupta,

E-mail: shresh0406@gmail.com

Copyright: (C) the author(s), publisher and licensee Medip Academy. This is an open-access article distributed under the terms of the Creative Commons Attribution Non-Commercial License, which permits unrestricted non-commercial use, distribution, and reproduction in any medium, provided the original work is properly cited.

\begin{abstract}
Endometriosis is an estrogen dependant disorder of reproductive-age women. It is uncommon after menopause, however, peripheral estrogen production may account for endometriosis in post-menopausal women. We reported a case of a 68 year old post-menopausal woman with an adnexal mass suspected malignant ovarian tumor on imaging and normal serum CA 125 levels. Total hysterectomy with bilateral salpingo-oophorectomy was done. The final histopathology revealed the diagnosis of ovarian endometriosis. Rarely, ovarian endometrioma can mimic ovarian malignancy in a post-menopausal woman.
\end{abstract}

Keywords: Post-menopausal endometriosis, Ovarian masses, Endometrioma, Ovarian malignancy, Estradiol, CA 125

\section{INTRODUCTION}

Endometriosis, a chronic benign inflammatory disease characterized by the presence of endometrial glands and stroma outside the uterine cavity, is an estrogen dependant disorder. The prevalence of endometriosis ranges from $6 \%$ to $10 \%$ in women of reproductive age group and $2 \%$ to $5 \%$ in post-menopausal women. ${ }^{1}$ Endometriosis should generally resolve with menopause, but in some postmenopausal women, it can be reactivated by the estrogen production from peripheral conversion or due to hormone replacement therapy (HRT) and rarely with normal estradiol levels which have been attributed to the ability of biosynthesizing estrogen via the aromatase activity. ${ }^{2}$

Endometriosis and ovarian malignancy can have similar risk factors like nulliparity, late childbearing and history of infertility, hence either can mimic the other. ${ }^{3}$

We presented a case of ovarian endometriosis in a postmenopausal woman with no previous history of hormonal therapy or endometriosis.

\section{CASE REPORT}

A 68 year old, non-obese, P5L5 post-menopausal lady, known case of type II diabetes mellitus and hypertension presented with abdominal distension for the last four months. The patient was well four months ago when she noticed abdominal distension which was insidious in onset, gradual in progression and was associated with weight loss and decreased appetite. There was no history of associated vomiting or abdominal pain or fever. There were no bladder and bowel complaints. General and systemic examination did not reveal any abnormality. On abdominal examination, a 20 week gravid uterus size mass was palpable in the hypogastrium, firm in consistency, smooth surface, regular margins, fixed, immobile and nontender. The lower margin of the mass could not be reached. On speculum examination cervix was flushed with the vagina and on bimanual examination a mass of 20 weeks gravid uterus size palpable more towards left fornix, going upwards and crossing the midline, firm in consistency, smooth surface and regular margins and non-tender. The uterus was not appreciated separate from the mass. Right 
fornix was free and non-tender. Routine investigations and levels of tumor markers were normal. A whole abdominal ultrasound revealed a well-defined cystic lesion of $16.2 \times 15.1 \mathrm{~cm}$ with echogenic debris within, atrophic uterus, thin endometrium, liver enlarged $(16.9 \mathrm{~cm})$ with grade 1 fatty changes, left kidney atrophic, right kidney normal. MRI of the abdomen confirmed the finding of a complex large abdominopelvic cyst $\left(16.2 \times 17.3 \times 14 \mathrm{~cm}^{3}\right)$ arising from the left adnexa with hemorrhagic signal intensity and T2 hypointense debris within, likely a complex hemorrhagic ovarian cyst, neoplastic etiology, uterus normal in size and left ovary was not visualized separately. Mild hydronephrosis in right kidney, mildly prominent right ureter seen up to the iliac crossing, compressed by fat displaced by lesion, fat planes between the pelvic lesion and right distal ureter well maintained. Laparotomy was done. Per operatively a left ovarian mass of $20 \times 20 \mathrm{~cm}$ was identified which was adherent to the large and small bowel. During dissection, inadvertent rupture of the mass occurred and 2 liters of chocolatecolored fluid got drained. Left-sided salpingooophorectomy was done and send for frozen section total hysterectomy with right salpingo-oophorectomy was done. Infracolic omentectomy was done because of a suspiciouslooking tumor. Other abdominal, pelvic organs, pelvic and para-aortic lymph nodes were palpated and were found to be within normal limits. The scrape cytology revealed a borderline epithelial ovarian tumor. The final histopathology revealed endometrial glands and stroma showing degenerative atypia and there was evidence of chronic hemorrhage as depicted by hemosiderin-laden foamy macrophages. All these features were consistent with findings of a benign endometriotic cyst. Omentum was normal.

Final histopathology confirmed the diagnosis of ovarian endometrioma. Immunohistochemistry demonstrated estrogen and progesterone receptor positivity.

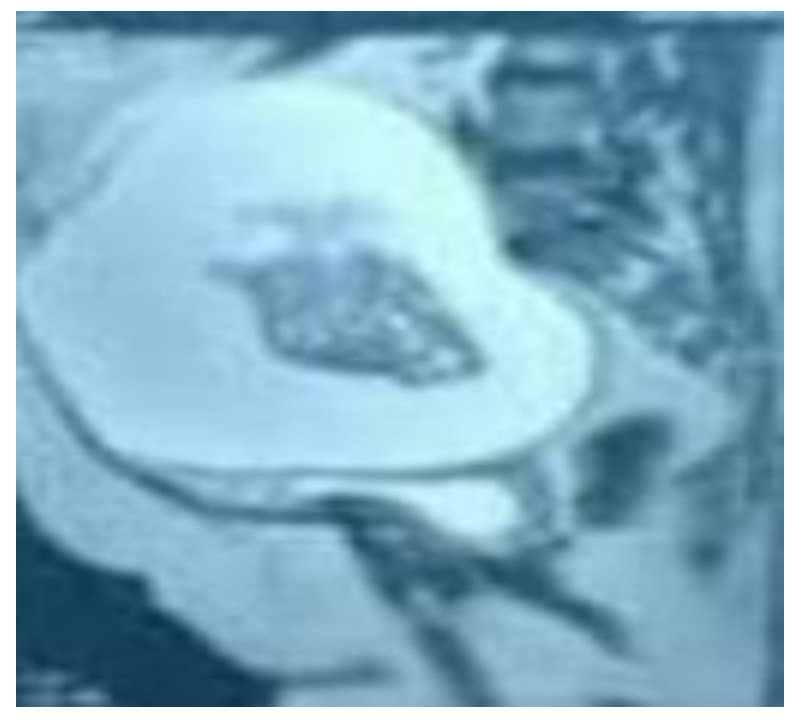

Figure 1: MRI showing large complex abdominopelvic cyst with hemorrhagic signal intensity and T2 hypointense debri within.

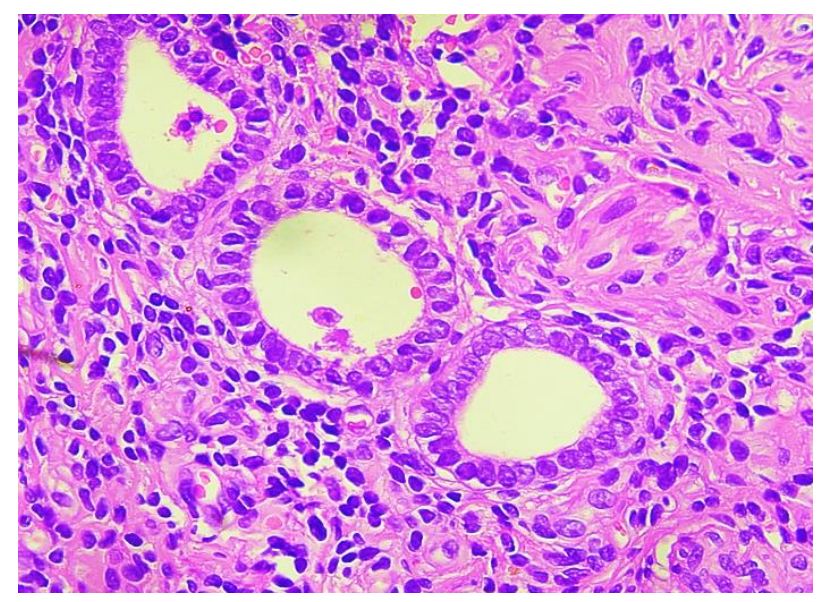

Figure 2: Histopathology section showing endometriotic focus in cyst wall.

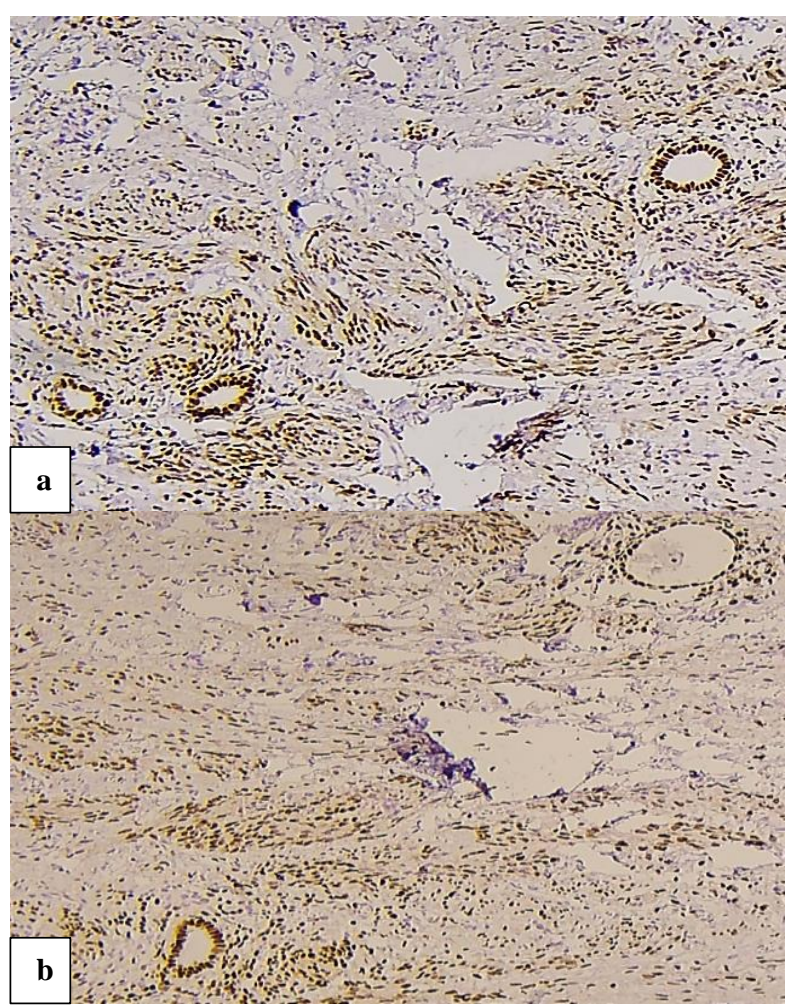

Figure 3 (a and b): Immunohistochemistry demonstrating estrogen and progesterone receptor positivity.

\section{DISCUSSION}

Endometriomas form a meagre $4.3 \%$ of the ovarian pathologies in the sixth decade of life primarily due to decreased levels of circulating estrogen. ${ }^{4}$ Peripheral conversion of steroid precursors to estrogen in tissues especially fat may induce endometriosis reactivation or by receiving HRT. ${ }^{2}$ Our case did not receive HRT, although she was non-obese, it did not seem to happen due to endogenous estrogens considering the absence of endometrial hyperplasia and appearance of symptoms several years after menopause. It had been explained in the 
various reports that an intrinsic signaling pathway can make endometriotic cells function as an independent unit where ectopic endometrial cells can biosynthesize estrogen from cholesterol in the absence of any external substance, such as adrenal androgens. ${ }^{5}$ An alternative explanation given for the progression of disease in postmenopausal women is that PGE2 secreted from macrophages and ectopic endometrial cells stimulates aromatase activity with local estrogen production. ${ }^{2}$

The expression of aromatase in retrograded endometrial cells was about 400 times. $^{6}$ This local estrogen production was the principal cause of steering endometriosis in postmenopausal women with normal serum estrogen levels. Also, estrogen plays a chief role in the recruitment of macrophages, the recruited macrophages play a key role in endometriosis production by secretion of vascular endothelial growth factor (VEGF) which may account for extensive vascularization contributing to massive size. ${ }^{7}$ This theory seemed to be a reasonable explanation in our case.

The coelomic metaplasia theory has also been put forward for the occurrence of postmenopausal ovarian endometriotic lesions. 8 Interleukins (interleukin (IL)1, IL2, IL6, IL8, IL10) and other inflammatory mediators (tumor necrosis factor alfa, interferon-gamma, monocyte chemotactic protein-1) could play a main role in the endometriosis pathophysiology, triggering celomic metaplasia etiopathogenic mechanism. 9

The rare progressive cases of endometrioma in postmenopausal women commencing a decade after menopause can be explained by genetic- epigenetic theory. ${ }^{10}$ The epigenetic mechanisms account for transmitting endometriosis at birth but the development of disease occurs later when additional incidents occur. It can also explain the growth of endometriosis with low circulating levels of estrogen. For each lesion, a specific set of incidents was specific and it can explain the heterogeneity of endometriotic lesions.

\section{CONCLUSION}

Endometriosis can occur at any age. Although its occurrence is rare after menopause, the possibility should always be considered. Regardless of their location and patient's age, these may reach up to large sizes. The possibility of malignancy should always be borne in mind. Ovarian endometriomas that are $9 \mathrm{~cm}$ or greater in diameter are a strong predictor for the development of ovarian cancer in postmenopausal women of 45 years of age or older.

Funding: No funding sources

Conflict of interest: None declared

Ethical approval: Not required

\section{REFERENCES}

1. Punnonen R, Klemi PJ, Nikkanen V. Postmenopausal endometriosis. Eur J Obstet Gynecol Reprod Biol. 1980;11(3):195-200.

2. Matsushima $\mathrm{T}$, Asakura H. Huge ovarian endometrioma that grew after menopause: case report. J Obstet Gynaecol Res. 2016;42(3):350-2.

3. Ness RB. Endometriosis and ovarian cancer: thoughts on shared pathophysiology. Am J Obstet Gynecol. 2003;189(1):280-94.

4. Oral E, Sozen I, Uludag S, Demirkiran F, Ilvan S, Oncul M, et al. The prevalence of endometrioma and associated malignant transformation in women over 40 years of age. J Gynecol Obstet Hum Reprod. 2020;49(5):101725.

5. Attar E, Bulun SE. Aromatase and other steroidogenic genes in endometriosis: translational aspects. Hum Reprod Update. 2006;12(1):49-56.

6. Noble LS, Takayama K, Zeitoun KM, Putman JM, Johns DA, Hinshelwood MM, et al. Prostaglandin E2 stimulates aromatase expression in endometriosis derived stromal cells. J Clin Endocrinol Metab. 1997;82(2):600-6.

7. Tuncay G, Kilic S, Yuksel B, Elmas C, Lortlar N, Erdogan D, et al. Heterogeneous appearance of VEGF (vascular endothelial growth factor) immunopositivity in cyst capsules of endometrioma. Acta Histochem. 2009;111(1):61-7.

8. Magtibay PM, Heppell J, Leslie KO. Endometriosisassociated invasive adenocarcinoma involving the rectum in a postmenopausal female. Dis Colon Rectum. 2001;44(10):1530-3.

9. Oral E, Ilvan S, Tustas E, Korbeyli B, Bese T, Demirkiran F, et al. Prevalence of endometriosis in malignant epithelial ovary tumours. Eur J Obstet Gynecol Reprod Biol. 2003;109(1):97-101.

10. Gordts S, Koninckx P, Brosens I. Pathogenesis of deep endometriosis. Fertil Steril. 2017;108(6):872-85.

Cite this article as: Zutshi V, Gupta S, Ahluwalia C, Monica R. Endometrioma mimicking ovarian malignancy in a post-menopausal woman. Int $\mathbf{J}$ Reprod Contracept Obstet Gynecol 2021;10:3226-8. 